\title{
Spina bifida and folate-related genes: A study of gene-gene interactions
}

Raffaella de Franchis, $M D^{1}$, Lorenzo D. Botto, $M D^{2}$, Gianfranco Sebastio, $M D^{1}$, Roberta Ricci, $M D^{3}$, Achille Iolascon, $M D^{4}$, Valeria Capra, $M D^{5}$, Generoso Andria, $M D^{1}$, and Pierpaolo Mastroiacovo, $M D^{3}$

\begin{abstract}
Purpose: To assess whether interactions of common alleles of two folate genes contribute to spina bifida risk. Methods: Case-control study, comparing 203 children with spina bifida to 583 controls. Results: Homozygosity for the $677 \mathrm{C}$-T allele of 5,10-methylenetetrahydrofolate reductase (MTHFR) alone was associated with an odds ratio for spina bifida of 1.57 (95\% confidence interval [Cl], 1.02-2.38). For the 844ins68 allele of cystathionine- $\beta$ synthase alone, the odds ratio was 0.83 (95\% Cl, 0.39-1.64). For the joint genotype, the odds ratio was 3.69 (95\% $\mathrm{Cl}, 1.04-13.50)$. Conclusions: Interactions between common alleles of folate genes might contribute to the risk for spina bifida. Genet Med 2002:4(3):126-130.
\end{abstract}

Key Words: spina bifida, folate, genetics, epidemiology, interaction

Spina bifida is a common and severe congenital anomaly that yearly affects approximately 1 in 1,000 newborns in Italy ${ }^{1}$ and 200,000 newborns or more worldwide. ${ }^{2,3}$ Clinical and epidemiologic evidence, such as the variability of occurrence rates by geography, time, socioeconomic status, and ethnicity, and the relatively low recurrence risk within families, suggests that the etiology of spina bifida involves interactions between multiple genetic and environmental factors. ${ }^{4,5}$ However, defining these factors and interactions has proven difficult. The protective effect of folic acid on the occurrence of spina bifida ${ }^{6-8}$ suggests that the study of folate metabolism might identify some of the genetic determinants of spina bifida. Several candidate genes have been studied, including 5,10-methylenetetrahydrofolate reductase (MTHFR), cystathionine- $\beta$ synthase (CBS), methionine synthase, and methionine synthase reductase. A pooled analysis suggests that homozygosity for the 677C-T allele of MTHFR in infants is associated with approximately a $70 \%$ increased risk for spina bifida. ${ }^{9}$ Common mutations of other genes, such as the 844ins 68 allele of CBS, ${ }^{10}$ have also been described, although their association with spina bifida is still unclear. Limited data are available on potential interactions among alleles of different folate-related genes. In 1997, Ramsbottom and associates ${ }^{11}$ from Ireland reported data on the $677 \mathrm{C}-\mathrm{T}$ allele of MTHFR and the 844 ins 68 allele of CBS and suggested that they indicated no interaction effects for spina bifida. We suggested that these data were consistent with the presence of interaction, ${ }^{12}$ although the original

\footnotetext{
From the ${ }^{1}$ Department of Pediatrics, Federico II University, Napoli, Italy; ${ }^{2}$ National Center on Birth Defects and Developmental Disabilities, Centers for Disease Control and Prevention, Atlanta, Georgia; ${ }^{3}$ Institute of Paediatrics, Catholic University, Roma, Italy; ${ }^{4}$ Department of Paediatrics, University of Bari, Bari, Italy; and ${ }^{5}$ Institute Giannina Gaslini, Genova, Italy. Pierpaolo Mastroiacovo, MD, Birth Defects Unit, Institute of Pediatrics, Largo Gemelli 8, 00168 Roma, Italy.

Received: October 24, 2001.
}

Accepted: February 11, 2002. authors thought otherwise. ${ }^{13}$ Subsequent studies yielded discordant findings, with one study from Germany reporting no interaction effects ${ }^{14}$ and another study from the United States reporting possible evidence for interaction. ${ }^{15}$ In this report, which expands findings reported in abstract, ${ }^{16}$ we assess the independent and joint effects of these two common alleles (677C-T and 844ins84) on the risk for spina bifida, using data from a large case-control study from Italy.

\section{MATERIALS AND METHODS}

\section{Study population}

The study population comprised 203 children with open spina bifida without other unrelated major malformations (case-subjects) and 583 healthy young adults and newborns (control-subjects). The subjects with spina bifida had been included in another study of MTHFR allelic variants. ${ }^{17}$ Of the 203 children with spina bifida, 173 (85\%) had myelomeningocele and $30(15 \%)$ had lipomeningocele. All affected children were enrolled from three spina bifida centers in three cities (Genova, Roma, Napoli) with the assistance of the Italian Federation of Spina Bifida and the Hydrocephalus Association. All children were born in Italy from Italian mothers. Children born in Sardinia were excluded. All affected children were alive at the time of the study, and their ages ranged from 1 month to 7 years. All had no affected sibs.

Of the 583 control subjects, 306 (52\%) were healthy young adults who had contributed samples to an anonymous DNA bank. Their ages ranged from 20 to 49 years. Some were healthy volunteers, others were parents of children with genetic diseases. None had a first-degree relative with a neural tube defect. The other 277 control subjects (48\%) were newborns whose blood spots were obtained from the regional newborn screening programs serving the areas where the case-subjects were born. The samples from all control subjects were anonymous, 
and information associated with these samples (newborns and adults alike) included sex, region of birth, and age group.

\section{Genetic assessment}

We assessed the subjects' genotype relative to the $677 \mathrm{C}-\mathrm{T}$ allele of MTHFR and the 844ins68 allele of CBS. DNA was prepared from blood following standard procedures. For blood spots, DNA was eluted from the paper (30 minutes at $96^{\circ} \mathrm{C}$ in $130 \mu \mathrm{L}$ of distilled water covered with a drop of paraffin oil) and was directly used for polymerase chain reaction amplification by adding the amplification mix to the template. The $677 \mathrm{C}$ - $\mathrm{T}$ allele and the 844 ins 68 alleles were detected as previously reported. ${ }^{18,19}$

\section{Estimating risks and interactions}

To describe the independent and joint effects of the gene variants, we used the "two-by-four table" approach discussed in relation to gene-environment ${ }^{19-21}$ and gene-gene interaction. ${ }^{12,19}$ We classified subjects in four mutually exclusive groups, by whether or not they were homozygous for the 677C-T allele and whether or not they had the 844 ins 68 allele (Table 1). The reference category was that in which neither the 677C-T allele nor the 844 ins68 allele was present. For the other three genotypic groups, we computed odds ratios, both unadjusted and adjusted for birth region and sex. We present unadjusted odds ratios with Fisher-exact confidence intervals (SABER, L. James, Centers for Disease Control and Prevention). We computed the attributable fraction among those with the genotype of interest (AF-gen), as

$$
\mathrm{AF}-\text { gen }=(\mathrm{OR}-1) / \mathrm{OR}
$$

which is analogous to the attributable fraction among the exposed in classic epidemiology, and the attributable fraction in the population (AF-pop), as

$$
\mathrm{AF}-\mathrm{pop}=\left[\mathrm{f}_{\mathrm{ca}}(\mathrm{OR}-1)\right] / \mathrm{OR}
$$

where $\mathrm{f}_{\mathrm{Ca}}$ is the fraction of cases with the genotype under study and OR is the odds ratio. ${ }^{22} \mathrm{We}$ used the SAS statistical package (version 6.12, SAS Institute, Inc., Cary, NC) to generate log- linear models (CATMOD procedure) that tested for differences between odds ratios. We evaluated interaction as departure of the joint effect from multiplicative and additive null models. Departure from a multiplicative model was assessed using the interaction term in a logistic regression model. Departure from an additive model of interaction was assessed using the relative excess risk due to interaction (RERI). ${ }^{23} \mathrm{~A}$ bootstrap procedure ${ }^{24}$ generated $95 \%$ bias-corrected confidence intervals of the RERI. ${ }^{25}$

\section{RESULTS}

We genotyped 203 subjects with spina bifida and 583 control-subjects for the 844 ins 68 allele of CBS and for the 677C-T allele of MTHFR. Of the control-subjects, $8.9 \%(N=52)$ had one 844 ins68 allele. Of the case-subjects, 9.4\% $(N=19)$ had one 844 ins 68 allele. No case or control subject had two 844 ins68 alleles. Of the controls, $16.6 \%(N=97)$ had two 677C-T alleles, 53.7\% $(N=313)$ had one 677C-T allele, and $29.7 \%(N=173)$ had none. The corresponding distribution among case-subjects was $25.6 \%(N=52), 43.8 \%(N=89)$, and $30.6 \%(N=62)$, respectively. These proportions were similar between subjects born in the North and in the South. Genotype frequencies were similar in the two sets of controls (newborns and adults) ${ }^{17}$; therefore, we pooled the sets.

The odds ratio for spina bifida associated with the joint genotype (homozygosity for 677C-T, heterozygosity for 844ins68) was 3.69, compared with 1.57 and 0.83 for 677C-T homozygosity alone and 844ins68 heterozygosity alone, respectively (Table 1). Adjusting for place of birth and sex did not change appreciably these results. Similar results were obtained when we analyzed separately lipomeningocele and meningocele.

When we assessed the additive interaction we found that the RERI, which estimates the amount by which the joint effect exceeds the sum of individual effects, was 2.30 (95\% confidence interval $[\mathrm{CI}],-0.45-14.02)$. In the absence of additive interaction, the RERI would be expected to be 0 . The odds ratio for multiplicative interaction, which estimates the ratio between joint effect and the product of individual effects, was

Table 1

\begin{tabular}{|c|c|c|c|c|c|c|c|c|}
\hline MTHFR $^{a}$ & $\mathrm{CBS}^{b}$ & Cases & Controls & $\begin{array}{l}\text { Odds } \\
\text { ratio }\end{array}$ & $95 \%$ CI & $\begin{array}{c}\text { AF-gen }^{c} \\
(\%)\end{array}$ & $\begin{array}{c}\text { AF-Pop }^{d} \\
(\%)\end{array}$ & $\begin{array}{l}\text { Genotype } \\
\text { frequency in } \\
\text { controls (\%) }\end{array}$ \\
\hline+ & + & 7 & 6 & 3.7 & $1.0-13.5$ & 72.9 & 2.5 & 1.0 \\
\hline+ & - & 45 & 91 & 1.6 & $1.0-2.4$ & 36.1 & 8.0 & 15.6 \\
\hline- & + & 12 & 46 & 0.8 & $0.4-1.6$ & -0.17 & & 7.9 \\
\hline- & - & 139 & 440 & Ref & & & & 75.5 \\
\hline Total & & 203 & 583 & & & & & \\
\hline
\end{tabular}

Estimated relative risk for spina bifida associated with the 677C-T allele of MTHFR and the 844Ins68 allele of the CBS gene, alone or in combination, Italy, 2001

${ }^{a}$ MTHFR: + , two 677C-T alleles of MTHFR; - , none or one 677C-T allele.

${ }^{b} \mathrm{CBS}:+$, one 844 ins68 allele; - , no 844 ins68 allele.

${ }^{c} \mathrm{AF}-\mathrm{gen}(\%)$ : attributable fraction (percent) among cases with genotype.

${ }^{d}$ AF- Pop (\%): attributable fraction (percent) among all cases in the population. 
2.87 (95\% CI, 0.76-10.75). In the absence of multiplicative interaction, such odds ratio would be expected to be 1 . We compared our findings with those from the literature (Table 2), rearranging the original data into the two-by-four table design.

\section{DISCUSSION}

The findings of this study suggest that interactions between common alleles of folate-related genes may contribute to the risk for spina bifida. Such interactions might be common. Of the control-subjects in this study, for example, 1 in 6 was homozygous for $677 \mathrm{C}-\mathrm{T}$ allele of MTHFR, 1 in 11 had the 844ins68 allele of CBS, and 1 in 97 had the joint genotype.

The results should be interpreted in light of the limitations of the study. First, the case group included prevalent rather than incident cases; did not include affected pregnancies that were electively terminated, that spontaneously aborted, or that ended in fetal death; and represented an unknown proportion of eligible cases. Such limitations might lead to distorted estimates if entry into the study was associated with genotype. For example, if the allelic variants affect survival, our results may be biased. ${ }^{26}$ Some studies have suggested that the $677 \mathrm{C}-\mathrm{T}$ allele frequency may be lower in older people..$^{27,28}$ However, such a lower allele frequency was found among people 80 years of age or older. Another possible limitation is the extent to which the control group is representative of the underlying population. The use of a subset of controls derived from newborn screening programs, the similarity of the genotype frequencies regardless of control subset, place of birth, age, and sex, and the consistency with independent estimates of allele frequency in Italian populations ${ }^{29-38}$ suggest that selection bias in the control group, if present, might be small. Moreover, bias is an unlikely explanation for the supra-multiplicative interaction, which is the main finding of the study. In fact, such interactions can be examined even without controls, assuming that alleles distribute randomly in the population. ${ }^{39}$ Finally, we do not measure blood folate and, thus, could not investigate its role in disease risk.

The biologic basis of the interaction between allelic variants of MTHFR and CBS is still unclear and awaits further bio- chemical and genetic studies. Both genes are involved in the metabolism of folate and its associated one-carbon transfers: MTHFR helps maintain an inflow of reduced methyl donors, used during synthesis of nucleotides and methylation of many substrates, including homocysteine ${ }^{40}$; CBS, which is expressed early in embryogenesis in the brain and neural crest ${ }^{41}$ controls one of the outflow paths of homocysteine. Homozygosity for the $677 \mathrm{C}-\mathrm{T}$ allele of MTHFR has been associated with an increased risk for spina bifida in several, though not all, studies. ${ }^{9}$ The role of 844ins68 allele of CBS is unclear. The 844ins68 allele has been reported to cause incomplete mRNA transcription compared with the common allele. ${ }^{19}$ This allele, however, unlike the $677 \mathrm{C}-\mathrm{T}$ allele, has been associated with lower, rather than higher, plasma homocysteine levels compared with the wild-type allele. ${ }^{42,43}$ The metabolic and clinical effects of the joint genotype (677C-T homozygosity and 844ins68 heterozygosity) are also inconsistent across studies. For example, the joint genotype has been associated with increased plasma homocysteine levels in some studies, ${ }^{44}$ whereas in others the 844ins68 allele has been reported to counter the homocysteine-raising effect of the $677 \mathrm{C}-\mathrm{T}$ allele. ${ }^{45}$ Clinically, the joint genotype has been associated with an increased risk for arterial and venous occlusive disease. ${ }^{46}$

As for spina bifida, our findings and those reported by Ramsbottom and associates ${ }^{11}$ (Table 2), in our view, reflect similar patterns of risk, i.e., no increased risk with the 844ins68 allele alone (odds ratio of 0.8 in both studies), an increased risk with 677C-T homozygosity alone (odds ratios of 1.6 and 2.0), and a further, disproportionate increased risk with the joint genotype (odds ratios of 3.7 and 5.1). A third study from Germany, ${ }^{14}$ however, reports neither an effect of 677C-T homozygosity nor an effect of the interaction with the 844ins68 allele (Table 2). A fourth study from the United States ${ }^{15}$ reports two sets of findings, using different sets of controls, one consistent with no interaction and one consistent with significant interaction (because these researchers did not report the full genotype distribution, we were unable to summarize their data in Table 2). These same investigators also had previously reported no effect of the $677 \mathrm{C}-\mathrm{T}$ allele on spina bifida risk. ${ }^{47} \mathrm{It}$ should be noted, therefore, that on balance, studies report ei-

Table 2

Independent and joint effects of $677 \mathrm{C}-\mathrm{T}$ and 844 ins 68 in three studies

\begin{tabular}{|c|c|c|c|c|c|c|c|c|c|c|c|c|c|}
\hline \multirow[b]{2}{*}{ MTHFR $^{a}$} & \multirow[b]{2}{*}{$\mathrm{CBS}^{b}$} & \multicolumn{4}{|c|}{ This study } & \multicolumn{4}{|c|}{ Ramsbottom et al. ${ }^{11}$} & \multicolumn{4}{|c|}{ Richter et al. ${ }^{14}$} \\
\hline & & Cases & Controls & Odds ratio & $95 \% \mathrm{CI}^{c}$ & Cases & Controls & Odds ratio & $95 \% \mathrm{CI}^{c}$ & Cases & Controls & Odds ratio & $95 \% \mathrm{CI}^{c}$ \\
\hline+ & + & 7 & 6 & 3.7 & $1.0-13.5$ & 7 & 5 & 5.1 & $1.4-20.9$ & 2 & 2 & 1.2 & $0.1-17.0$ \\
\hline+ & - & 45 & 91 & 1.6 & $1.0-2.4$ & 19 & 34 & 2.0 & $1.0-3.9$ & 26 & 25 & 1.3 & $0.7-2.4$ \\
\hline- & + & 12 & 46 & 0.8 & $0.4-1.6$ & 16 & 76 & 0.8 & $0.4-1.4$ & 20 & 40 & 0.6 & $0.3-1.1$ \\
\hline- & - & 139 & 440 & Ref & & 86 & 315 & Ref & & 136 & 166 & Ref & \\
\hline Total & & 203 & 583 & & & 128 & 430 & & & 184 & 233 & & \\
\hline
\end{tabular}

${ }^{a}$ MTHFR: +, two C677T alleles of MTHFR; -, no or one C677T allele.

${ }^{b} \mathrm{CBS}$ : +, one 844ins68 allele of CBS; -, no 844ins68 allele.

${ }^{c} 95 \%$ CI, Fisher exact. 
ther both effects - of 677C-T homozygosity alone and the interaction with 844ins68 - or neither.

The practical impact of MTHFR-CBS interactions, assuming they are real, can be inferred from their estimated attributable fractions (Table 1). The attributable fraction among those with the genotype (AF-Gen), for example, shows that, even among cases with the genotype, the latter might not be causal. The attributable fraction in the population (AF-pop) shows that approximately 1 in 40 cases in this population (2.5) was due to the interaction, assuming causality. Such proportion might be different in other populations with different prevalences of the 677C-T and 844ins68 alleles. Such estimates, if replicated across other studies and populations, can also help understand better why folic acid works in preventing spina bifida and to what degree genetic susceptibility is involved in different populations.

In summary, our findings support a possible interaction of common alleles in the risk for spina bifida, at least in this population from Italy. We suggest that the 844ins68 allele of CBS be included in studies of putative genetic determinants of spina bifida, in an effort to delineate the role of complex genotypes in disease risk. Because of the ethnic and geographic variation of the frequency of $677 \mathrm{C}-\mathrm{T}$ allele ${ }^{9}$ and possibly also of the 844ins68 allele, ${ }^{11,19,48,49}$ it is possible that failure to consider interacting genes may contribute to the variability of the risk estimates.

A further methodologic consideration relates to the impact of sample size on the power to detect interactions. All studies to date (Table 2) have generated effect estimates that are relatively imprecise, with wide confidence intervals. Thus one must avoid the twin pitfalls of believing an effect without considering its potential random variation or dismissing findings as negative solely on the basis of a $P$ value. Convincing and precise answers on the presence or absence of interaction awaits evidence from larger, carefully conducted studies.

Ideally, such studies also should evaluate interactions with environmental factors, such as blood folate levels ${ }^{50}$ and multivitamin supplement use. ${ }^{51}$ Other gene-environment ${ }^{52}$ and genegene interactions $\mathrm{s}^{52,53}$ might also occur. If feasible, interactions between maternal and fetal genotype should also be investigated. For example, it has been suggested that, although the fetal genotype might play the preeminent role, the coexistence of the 677C-T homozygote genotype in the mother might further stress the fetus, perhaps by exposing it to suboptimal folate levels and, thus, increase the fetus's risk for spina bifida. ${ }^{54}$ Ultimately, the prevailing hope is that the study of how interactions between multiple genes and environmental factors contribute to health and disease may generate further opportunities for primary prevention, particularly as relates to relatively common conditions in genetically diverse populations.

\section{Acknowledgments}

The financial support of MURST COFIN 2000 (618253303) to G. Sebastio, of Ministero Sanità, Istituto G. Gaslini for G. Andria, and of Telethon (project E 4399) and MURST COFIN 98/99 (9806183096-008) to P. Mastroiacovo is gratefully ac- knowledged. We thank Dr. Quanhe Yang and Dr. Yecai Liu for their help in the analysis of additive interactions. We are grateful to the Spina Bifida Associations for their cooperation and support.

\section{References}

1. Mastroiacovo PP, Bianchi F. [The descriptive epidemiology of congenital defects at birth in Italy]. Epidemiol Prev 1991;13:94-103

2. Moore CA, Li S, Li Z, Hong SX, Gu HQ, Berry RJ, Mulinare J, Erickson JD. Elevated rates of severe neural tube defects in a high-prevalence area in northern China. Am J Med Genet 1997;73:113-118.

3. Shibuya K, Murray CJL. Congenital anomalies. In: Murray CJL, Lopez AD, eds. Boston: Harvard University Press, 1998:455-512.

4. Elwood JM, Little J, Elwood JH. Epidemiology and control of neural tube defects. New York: Oxford University Press, 1992.

5. Botto LD, Moore CA, Khoury MJ, Erickson JD. Medical progress: neural-tube defects [review]. N Engl J Med 1999;341:1509-1519.

6. Czeizel AE, Dudas I. Prevention of the first occurrence of neural-tube defects by periconceptional vitamin supplementation. N Engl J Med 1992;327:1832-1835.

7. MRC Vitamin Study Research Group. Prevention of neural tube defects: results of the Medical Research Council Vitamin Study. Lancet 1991;338:131-137.

8. Berry RJ, Li Z, Erickson JD, Li S, Moore CA, Wang H, Mulinare J, Zhao P, Wong LY, Gindler J, Hong SX, Correa A. Prevention of neural-tube defects with folic acid in China. China-U.S. Collaborative Project for Neural Tube Defect Prevention. NEngl J Med 1999;341:1485-1490.

9. Botto LD, Yang Q. 5,10-Methylenetetrahydrofolate reductase gene variants and congenital anomalies: a HuGE review. Am J Epidemiol 2000;151:862-877.

10. Sebastio G, Sperandeo MP, Panico M, de Franchis R, Kraus JP, Andria G. The molecular basis of homocystinuria due to cystathionine beta-synthase deficiency in Italian families, and report of four novel mutations. Am J Hum Genet 1995;56:13241333.

11. Ramsbottom D, Scott JM, Molloy A, Weir DG, Kirke PN, Mills JL, Gallagher PM, Whitehead AS. Are common mutations of cystathionine beta-synthase involved in the aetiology of neural tube defects? Clin Genet 1997;51:39-42.

12. Botto LD, Mastroiacovo P. Exploring gene-gene interactions in the etiology of neural tube defects. Clin Genet 1998;53:456-459.

13. Whitehead AS, Molloy AM, Ramsbottom D, Weir DG, Kirke PN, Mills JL, Gallagher PM, Scott JM. Gene-gene interactions and neural tube defects [letter]. Clin Genet 1999;55:133-134.

14. Richter B, Stegmann K, Roper B, Boddeker I, Ngo ET, Koch MC. Interaction of folate and homocysteine pathway genotypes evaluated in susceptibility to neural tube defects (NTD) in a German population. J Hum Genet 2001;46:105-109.

15. Speer MC, Nye J, McLone D, Worley G, Melvin EC, Viles KD, Franklin A, Drake C, Mackey J, George TM. Possible interaction of genotypes at cystathionine beta-synthase and methylenetetrahydrofolate reductase (MTHFR) in neural tube defects. NTD Collaborative Group. Clin Genet 1999;56:142-144.

16. de Franchis R, Mandato C, Buoninconti A, Sperandeo MP, Capra V, De Marco P, et al. Risk factors for neural tube defects: analysis of common genetic variants of methylenetetrahydrofolate reductase and cystathionine beta-synthase [abstract]. Am J Hum Genet 1997;61:151.

17. de Franchis R, Buoninconti A, Mandato C, Pepe A, Sperandeo MP, Del Gado R, Capra V, Salvaggio E, Andria G, Mastroiacovo P. The C677T mutation of the 5,10methylenetetrahydrofolate reductase gene is a moderate risk factor for spina bifida in Italy. J Med Genet 1998;35:1009-1013.

18. Frosst P, Blom HJ, Milos R, Goyette P, Sheppard CA, Matthews RG, Boers GJ, den Heijer M, Kluijtmans LA, van den Heuvel LP. A candidate genetic risk factor for vascular disease: a common mutation in methylenetetrahydrofolate reductase [letter]. Nat Genet 1995;10:111-113.

19. Sperandeo MP, de Franchis R, Andria G, Sebastio G. A 68-bp insertion found in a homocystinuric patient is a common variant and is skipped by alternative splicing of the cystathionine beta- synthase mRNA [letter]. Am J Hum Genet 1996;59:13911393.

20. Botto LD, Khoury MJ. Facing the challenge of gene-environment interaction: the two-by-four table and beyond. Am J Epidemiol 2001;153:1016-1020.

21. Khoury MJ, Adams MJ Jr, Flanders WD. An epidemiologic approach to ecogenetics. Am J Hum Genet 1988;42:89-95.

22. Miettinen OS. Proportion of disease caused or prevented by a given exposure, trait or intervention. Am J Epidemiol 1974;99:325-332.

23. Rothman KJ, Greenland S. Modern epidemiology. 2nd ed. Philadelphia: LippincottRaven, 1998.

24. Efron B, Tibshirani RJ. An introduction to the bootstrap. New York: Chapman \& Hall, 1993. 


\section{de Franchis et al.}

25. Assmann SF, Hosmer DW, Lemeshow S, Mundt KA. Confidence intervals for measures of interaction. Epidemiology 1996;7:286-290.

26. Posey DL, Khoury MJ, Mulinare J, Adams MJ Jr, Ou CY. Is mutated MTHFR a risk factor for neural tube defects? [letter]. Lancet 1996;347:686-687.

27. Heijmans BT, Gussekloo J, Kluft C, Droog S, Lagaay AM, Knook DL, Westendorp RG, Slagboom EP. Mortality risk in men is associated with a common mutation in the methylene-tetrahydrofolate reductase gene (MTHFR). Eur J Hum Genet 1999;7: 197-204.

28. Matsushita S, Muramatsu T, Arai H, Matsui T, Higuchi S. The frequency of the methylenetetrahydrofolate reductase-gene mutation varies with age in the normal population [letter]. Am J Hum Genet 1997;61:1459-1460.

29. Ames PR, Tommasino C, D'Andrea G, Iannaccone L, Brancaccio V, Margaglione M. Thrombophilic genotypes in subjects with idiopathic antiphospholipid antibodiesprevalence and significance. Thromb Haemost 1998;79:46-49.

30. Cattaneo M, Tsai MY, Bucciarelli P, Taioli E, Zighetti ML, Bignell M, Mannucci PM. A common mutation in the methylenetetrahydrofolate reductase gene $(\mathrm{C} 677 \mathrm{~T})$ increases the risk for deep-vein thrombosis in patients with mutant factor $\mathrm{V}$ (factor V:Q506). Arterioscler Thromb Vasc Biol 1997;17:1662-1666.

31. de Franchis R, Mancini FP, D’Angelo A, Sebastio G, Fermo I, de Stefano V, Margaglione M, Mazzola G, di Minno G, Andria G. Elevated total plasma homocysteine and $677 \mathrm{C} \rightarrow \mathrm{T}$ mutation of the 5,10- methylenetetrahydrofolate reductase gene in thrombotic vascular disease [letter]. Am J Hum Genet 1996;59:262-264.

32. Girelli D, Friso S, Trabetti E, Olivieri O, Russo C, Pessotto R, Faccini G, Pignatti PF, Mazzucco A, Corrocher R. Methylenetetrahydrofolate reductase C677T mutation, plasma homocysteine, and folate in subjects from northern Italy with or without angiographically documented severe coronary atherosclerotic disease: evidence for an important genetic-environmental interaction. Blood 1998;91:4158-4163.

33. Grandone E, Margaglione M, Colaizzo D, Montanaro S, Pavone G, Di Minno G. Presence of FV Leiden and MTHFR mutation in a patient with complicated pregnancies [letter]. Thromb Haemost 1997;77:1036-1037.

34. Margaglione M, D'Andrea G, d'Addedda M, Giuliani N, Cappucci G, Iannaccone L, Vecchione G, Grandone E, Brancaccio V, Di Minno G. The methylenetetrahydrofolate reductase TT677 genotype is associated with venous thrombosis independently of the coexistence of the FV Leiden and the prothrombin A20210 mutation. Thromb Haemost 1998;79:907-911.

35. Sacchi E, Tagliabue L, Duca F, Mannucci PM. High frequency of the C677T mutation in the methylenetetrahydrofolate reductase (MTHFR) gene in Northern Italy [letter]. Thromb Haemost 1997;78:963-964.

36. Tosetto A, Missiaglia E, Frezzato M, Rodeghiero F. The VITA project. C677T mutation in the methylene-tetrahydrofolate reductase gene and risk of venous thromboembolism. Br J Haematol 1997;97:804-806.

37. Abbate R, Sardi I, Pepe G, Marcucci R, Brunelli T, Prisco D, Fatini C, Capanni M, Simonetti I, Gensini GF. The high prevalence of thermolabile 5-10 methylenetetrahydrofolate reductase (MTHFR) in Italians is not associated to an increased risk for coronary artery disease (CAD). Thromb Haemost 1998;79:727-730.

38. Motti C, Gnasso A, Bernardini S, Massoud R, Pastore A, Rampa P, Federici G, Cortese C. Common mutation in methylenetetrahydrofolate reductase. Correlation with homocysteine and other risk factors for vascular disease. Atherosclerosis 1998; 139:377-383.

39. Yang Q, Khoury MJ. Evolving methods in genetic epidemiology. III. Gene-environment interaction in epidemiologic research. Epidemiol Rev 1997;19:33-43.
40. Rosenblatt DS. Inherited disorders of folate transport and metabolism. In: Scriver CR, Beaudet AL, Sly WS, Valle D, eds. New York: McGraw Hill, 1995:3111-3128.

41. Quere I, Paul V, Rouillac C, Janbon C, London J, Demaille J, Kamoun P, Dufier JL, Abitbol M, Chasse JF. Spatial and temporal expression of the cystathionine betasynthase gene during early human development. Biochem Biophys Res Commun 1999;254:127-137.

42. Aras O, Hanson NQ, Yang F, Tsai MY. Influence of $699 \mathrm{C} \rightarrow \mathrm{T}$ and $1080 \mathrm{C} \rightarrow \mathrm{T}$ polymorphisms of the cystathionine beta-synthase gene on plasma homocysteine levels. Clin Genet 2000;58:455-459.

43. Tsai MY, Yang F, Bignell M, Aras O, Hanson NQ. Relation between plasma homocysteine concentration, the 844ins68 variant of the cystathionine beta-synthase gene, and pyridoxal-5'-phosphate concentration. Mol Genet Metab 1999;67:352356.

44. Andria G, Buoninconti A, Sperandeo MP, de Franchis R, D'Angelo A, Sebastio G, et al. Intermediate hyperhomocysteinemia and the 844ins 68 mutation of the cystathionine-beta-synthase gene [abstract]. Am J Hum Genet 1998;63(suppl):A207.

45. Dekou V, Gudnason V, Hawe E, Miller GJ, Stansbie D, Humphries SE. Gene-environment and gene-gene interaction in the determination of plasma homocysteine levels in healthy middle-aged men. Thromb Haemost 2001;85:67-74.

46. de Franchis R, Fermo I, Mazzola G, Sebastio G, Di Minno G, Coppola A, Andria G, D'Angelo A. Contribution of the cystathionine beta-synthase gene (844ins68) polymorphism to the risk of early-onset venous and arterial occlusive disease and of fasting hyperhomocysteinemia. Thromb Haemost 2000;84:576-582.

47. Speer M, Worley G, Mackey J, Melvin E, Oakes W, George T. The thermolabile variant of methylenetetrahydrofolate reductase (MTHFR) is not a major risk factor for neural tube defect in American Caucasians. Neurogenetics 1997;1:149-150.

48. Kluijtmans LA, Boers GH, Trijbels FJ, van Lith-Zanders HM, van den Heuvel LP, Blom HJ. A common 844INS68 insertion variant in the cystathionine beta-synthase gene. Biochem Mol Med 1997;62:23-25.

49. Pepe G, Vanegas OC, Rickards O, Giusti B, Comeglio P, Brunelli T, Marcucci R, Prisco D, Gensini GF, Abbate R. World distribution of the T833C/844INS68 CBS in cis double mutation: a reliable anthropological marker. Hum Genet 1999;104:126129

50. Christensen B, Arbour L, Tran P, Leclerc D, Sabbaghian N, Platt R, Gilfix BM, Rosenblatt DS, Gravel RA, Forbes P, Rozen R. Genetic polymorphisms in methylenetetrahydrofolate reductase and methionine synthase, folate levels in red blood cells, and risk of neural tube defects. Am J Med Genet 1999;84:151-157.

51. Shaw GM, Rozen R, Finnell RH, Wasserman CR, Lammer EJ. Maternal vitamin use, genetic variation of infant methylenetetrahydrofolate reductase, and risk for spina bifida. Am J Epidemiol 1998;148:30-37.

52. Christensen B, Yang H, Gravel RA, Rozen R. A common variant in methionine synthase reductase combined with low cobalamin (vitamin B12) increases risk for spina bifida. Mol Genet Metab 1999;67:317-323.

53. Morrison K, Papapetrou C, Hol FA, Mariman EC, Lynch SA, Burn J, Edwards YH. Susceptibility to spina bifida; an association study of five candidate genes. Ann Hum Genet 1998;62:379-396.

54. Shields DC, Kirke PN, Mills JL, Ramsbottom D, Molloy AM, Burke H, Weir DG, Scott JM, Whitehead AS. The "thermolabile" variant of methylenetetrahydrofolate reductase and neural tube defects: an evaluation of genetic risk and the relative importance of the genotypes of the embryo and the mother. Am J Hum Genet 1999;64:1045-1055. 